\title{
The long-term recurrence of Rathke's cleft cysts as predicted by histology but not by surgical procedure
}

\author{
Yasuyuki Kinoshita, MD, PhD, ${ }^{1}$ Atsushi Tominaga, MD, PhD, ${ }^{2}$ Satoshi Usui, MD, ${ }^{1}$ \\ Kazunori Arita, MD, PhD, ${ }^{3}$ Tetsuhiko Sakoguchi, MD, PhD, ${ }^{2}$ Kazuhiko Sugiyama, MD, PhD, ${ }^{4}$ and \\ Kaoru Kurisu, MD, PhD'
}

\begin{abstract}
1Department of Neurosurgery, Graduate School of Biomedical and Health Sciences, Hiroshima University; ${ }^{2}$ Department of Neurosurgery, Hiroshima Prefectural Hospital; and ${ }^{4}$ Department of Clinical Oncology and Neuro-oncology Program, Hiroshima University Hospital, Hiroshima; and ${ }^{3}$ Department of Neurosurgery, Graduate School of Medical and Dental Sciences, Kagoshima University, Kagoshima, Japan
\end{abstract}

OBJECTIVE Patients with symptomatic Rathke's cleft cysts (RCCs) managed by surgical treatment often experience recurrence. The authors attempted to clarify the outcome of surgically treated RCCs over a long-term follow-up period. METHODS Ninety-one consecutive RCC patients with a follow-up period of more than 12 months (mean 80.2 months, range 12-297 months) were retrospectively studied. The authors examined the clinical features and postoperative course of patients who experienced a reaccumulation of cyst contents visible on MRI after the initial surgery, and they investigated data from the patients who underwent reoperation for symptomatic recurrent RCCs.

RESULTS Reaccumulation of cyst contents occurred in 36 patients (39.6\%). In 34 of these patients, a reaccumulation occurred in the first 5 years after surgery. The initial cysts in these patients were most often large, with squamous metaplasia in the cyst walls. Thirteen patients (14.3\%) with recurrent symptoms underwent a reoperation, and 10 of the 13 patients had a reaccumulation of RCCs within the 1st year after surgery. The reoperations were performed in the 1st year $(61.5 \%)$ or several years later $(23.1 \%)$. Patients were likely to initially have had a visual disturbance and the cyst walls likely included squamous metaplasia. However, no association was observed between the incidence of reaccumulation/reoperation of RCCs and the surgical procedure for RCCs.

CONCLUSIONS The reaccumulation rate of RCC is high in the long-term period, and it is associated with the histological findings but not with the surgical procedure. Long-term monitoring, for a period of at least 5 years, should therefore be conducted to identify and assess any RCC reaccumulation.

http://thejns.org/doi/abs/10.3171/2015.8.JNS151282

KEY WORDS Rathke's cleft cysts; long-term outcome; transsphenoidal surgery; recurrence; reaccumulation; oncology

$\mathrm{R}$ ATHKE's cleft cysts (RCCs) are cystic sellar and suprasellar lesions that are thought to originate from the remnants of Rathke's pouch. These common sellar lesions have been found in $3.7 \%$ of 1000 autopsies. ${ }^{13}$ They are usually asymptomatic; ${ }^{1,12,17}$ however, some RCCs can be symptomatic due to their mass effect and/or due to inflammatory injury of the surrounding structures. ${ }^{3,4,14}$

Symptomatic RCCs are managed surgically by draining the cyst contents with or without biopsy or removal of the cyst wall. The removal of the entire cyst wall is associated with lower rates of cyst recurrence. ${ }^{2,8}$ It should be noted that postoperative endocrine dysfunction is often caused by the aggressive removal of the cysts., ${ }^{1,2,5,16}$ Moreover, it has been reported that the extended resection of the cyst wall was not found to be associated with a decreased risk of relapse. . $^{1,5,10}$

Recently, most surgical treatments for RCCs have involved the drainage of the cyst contents and the safe removal of as much of the capsule as possible, with or without marsupialization. ${ }^{14,17}$ However, there is no consensus as to which surgical procedures are the most effective for treating symptomatic RCCs. 
The reported recurrence rates of postoperative RCCs in patients who were surgically treated for RCC have ranged from $10 \%$ to $22 \% .^{1,5-9,11,15,16}$ The different findings reported in previous studies may be due to variations in the surgical procedures, follow-up periods, or follow-up protocols that were employed. The aim of the present study was to clarify the recurrence rate of RCCs in patients who were treated surgically (with uniform surgical procedures) and in those who underwent postoperative routine MRI for a long-term follow-up period (mean 80.2 months), and also to assess the factors that predict the recurrence of RCCs.

\section{Methods}

\section{Patient Population}

We retrospectively studied 91 consecutive patients who were diagnosed with RCC based on MRI and intraoperative findings at Hiroshima University Hospital between 1986 and 2014. The mean age of the 36 male and 55 female patients at the time of operation was 53.0 years (range 12-81 years). The minimum follow-up period for inclusion in this study was 12 months.

\section{Preoperative Evaluation}

All patients underwent physical and ophthalmological examinations, an endocrinological workup, and MRI, and their detailed general and neurological histories were recorded. Their anterior pituitary function was evaluated by their response to induced hypoglycemia and/or to the administration of corticotropin-releasing hormone $(100 \mu \mathrm{g})$, thyrotropin-releasing hormone $(500 \mu \mathrm{g})$, luteinizing hormone-releasing hormone $(100 \mu \mathrm{g})$, and/or arginine (30 g).

\section{Surgical Procedures}

Prior to 1995, microscopic transsphenoidal surgery (TSS) was performed via the sublabial transsphenoidal approach. Endoscopic assistance for TSS was introduced in 1995, and a completely endoscopic procedure was adopted in 2010. The sublabial transsphenoidal approach shifted to the endonasal transsphenoidal approach in 2002. The surgical procedures included drainage of the cyst contents and a biopsy of the cyst wall with or without a stoma between the cyst and the suprasellar cistern or sphenoid sinus. Prior to 2005, simple cyst drainage and a biopsy were performed. In cases after 2005, an attempt was made to create a stoma of the suprasellar cistern with a fat graft placed inside the cyst to prevent CSF leakage. The sellar floor was reconstructed using autologous bone from the vomer. In the inital operations, we did not attempt the removal of the entire cyst wall and did not irrigate the cyst cavity using absolute ethanol. Six of the patients in the present series first underwent transcranial surgeries for RCCs.

\section{Pathological Tissue Analysis}

The tissue specimens obtained during these operations were fixed in formalin, embedded in paraffin, sectioned, and stained with $\mathrm{H} \& \mathrm{E}$. A histopathological diagnosis of RCC was established in 79 patients. A histopathological diagnosis was not obtained in the other 12 patients, either because the biopsy failed $(n=9)$ or because a biopsy was not performed $(\mathrm{n}=3)$. In those 12 patients, we diagnosed RCC based on MRI and intraoperative findings and on the patients' postoperative courses.

\section{Treatment Follow-Up and the Definition of Reaccumulation and Reoperation}

The mean follow-up period was 80.2 months (median 70 months, range 12-297 months). All patients generally underwent postoperative MRI at 3 months after surgery and annually thereafter (even patients who were asymptomatic with no reaccumulation of the cyst contents). We defined reaccumulation as the enlargement (even a slight enlargement) of the reduced or resolved postoperative cyst cavity on sagittal MR images (Fig. 1). Asymptomatic patients exhibiting the reaccumulation of cyst contents were followed up with MRI performed every 3 to 6 months. Reoperation was performed in patients who again devel-
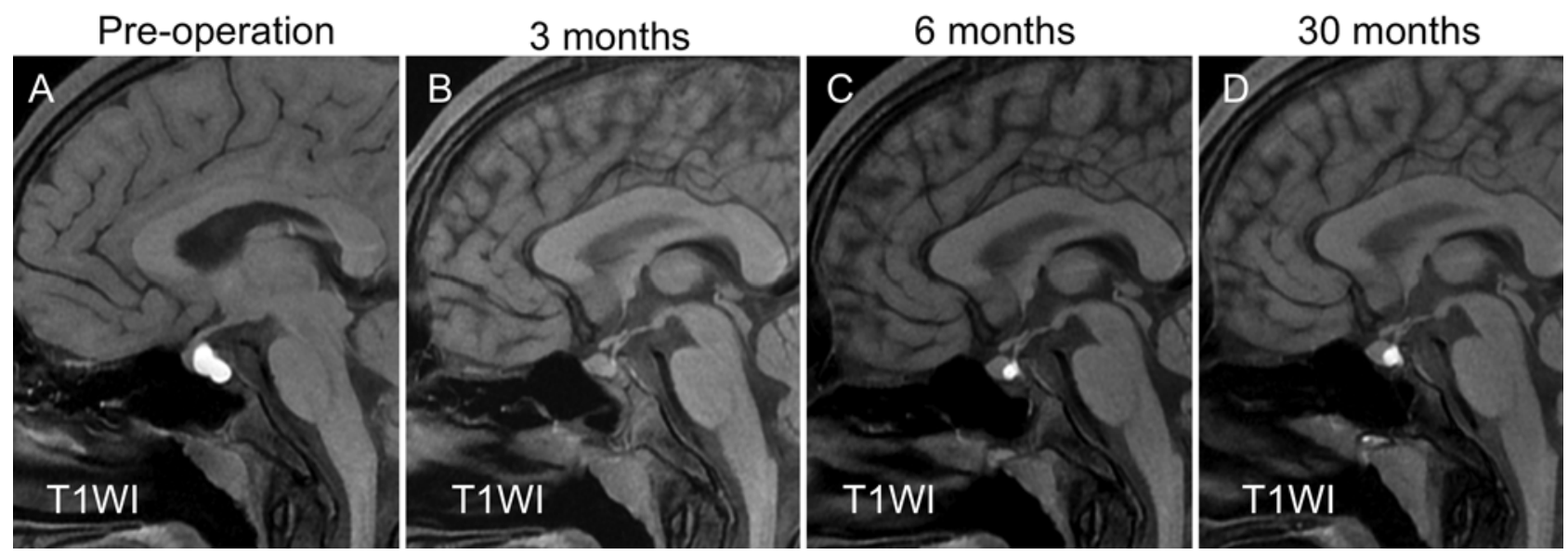

FIG. 1. Sagittal T1-weighted MR images obtained in a 15-year-old boy who presented with a chronic headache. A: Preoperative image showing a high-intensity cyst. B: Image obtained 3 months after undergoing surgery for drainage and biopsy showing that the cyst has disappeared. C: Image obtained 6 months after surgery showing the reaccumulation of the cyst contents. D: Image obtained 30 months after surgery showing a slightly enlarged cyst. 

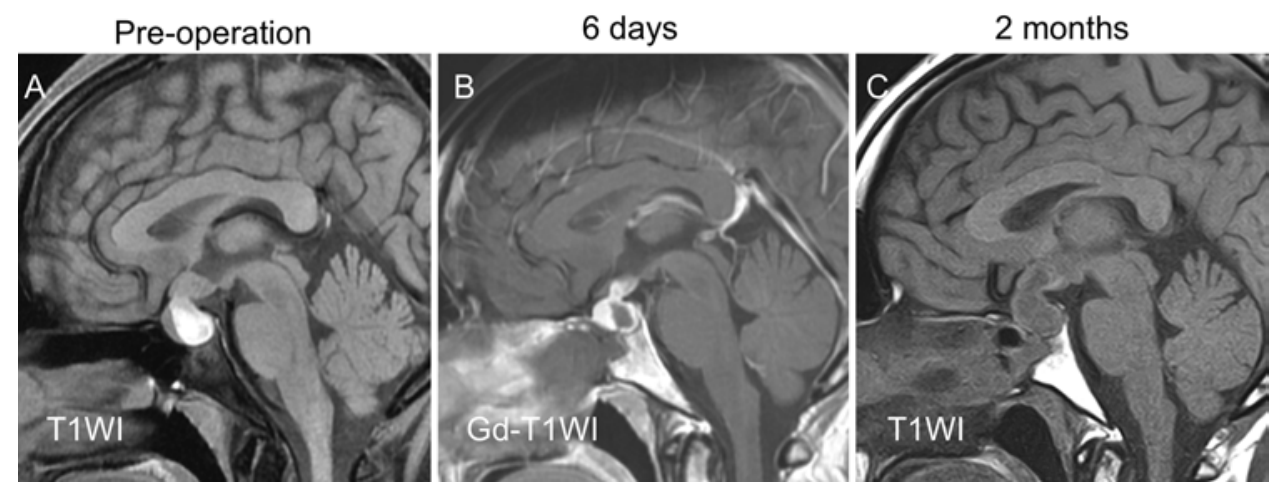

FIG. 2. Sagittal T1-weighted MR images obtained in a 32-year-old woman who presented with a chronic headache and amenorrhea. A: Preoperative image showing an isointense to high-intensity cyst. B: Gd-enhanced image obtained 6 days after surgery for drainage and biopsy showing that the cyst has disappeared. C: Image obtained 2 months after surgery showing the reaccumulation of the cyst contents. The patient underwent reoperation due to recurrent symptoms.

oped symptoms due to RCC reaccumulation after the initial surgery (Fig. 2). The incidence of reoperation reflects the incidence of symptomatic reaccumulation of RCC in this study.

\section{Statistical Analysis}

All statistical analyses were performed using the software package SPSS 16.0 J for Windows (SPSS Inc.). The Mann-Whitney U-test and Fisher's exact test were used for comparisons. The values are expressed as medians. A $p$ value of $<0.05$ was considered to be statistically significant.

\section{Results}

The Incidence and Timing of Reaccumulation and Reoperation

A reaccumulation of the cyst contents was observed in the postoperative MRI examinations of 36 patients (39.6\%) (Fig. 3). In most patients, this reaccumulation occurred in the first 5 years after surgery $(\mathrm{n}=34,94.4 \%)$, and such a reaccumulation could even be found more than 10 years after surgery (Fig. 4). Thirteen patients with recurrent symptoms underwent a reoperation. In most of the patients who underwent a reoperation, the reaccumulation of cyst contents occurred in the 1st year after surgery $(\mathrm{n}=10,76.9 \%)$. However, the timing of the reoperations was bimodal: either during the 1st year after surgery $(\mathrm{n}=$ $8,61.5 \%)$ or several years after the initial surgery $(\mathrm{n}=3$, 23.1\%) (Fig. 5). No patients required a reoperation after 10 years of follow-up.

\section{The Clinical Features of Patients With Reaccumulation}

The details of the clinical features at the initial surgery of patients with a reaccumulation are shown in Table 1 . The patients with a reaccumulation had a larger initial cyst

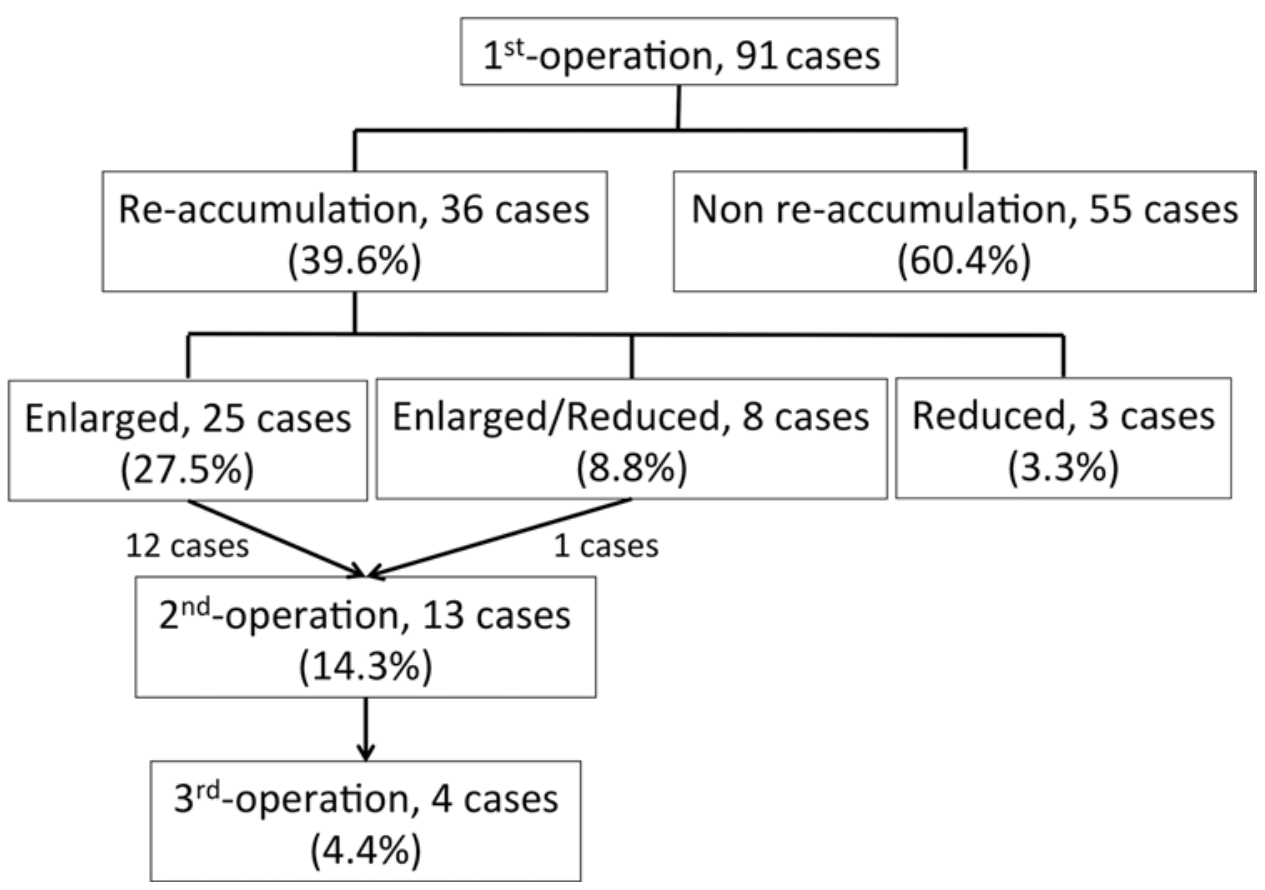

FIG. 3. Schematic showing the outcomes of 91 patients who underwent surgical treatment. 
TABLE 1. The clinical features at the initial surgery in patients with reaccumulation of cyst contents and those who underwent reoperation*

\begin{tabular}{|c|c|c|c|c|c|c|c|}
\hline \multirow[b]{2}{*}{ Characteristic } & \multirow[b]{2}{*}{ Total Cases $(n=91)$} & \multicolumn{3}{|c|}{ Reaccumulation } & \multicolumn{3}{|c|}{ Reop } \\
\hline & & No $(n=55)$ & Yes $(n=36)$ & $p$ Value & No $(n=78)$ & Yest $(n=13)$ & $\mathrm{p}$ Value \\
\hline Age in years, median & 53.0 & 54.0 & 48.0 & 0.2944 & 54.0 & 48.0 & 0.3763 \\
\hline M:F ratio & $36 / 55$ & $25 / 30$ & $11 / 25$ & 0.1911 & $32 / 46$ & $4 / 9$ & 0.5544 \\
\hline \multicolumn{8}{|l|}{ Symptoms } \\
\hline Visual disturbance & $39(42.9)$ & $21(38.2)$ & $18(50.0)$ & 0.2866 & $29(37.2)$ & $10(76.9)$ & 0.0131 \\
\hline Headache & $29(31.9)$ & $17(30.9)$ & $12(33.3)$ & 0.8218 & $27(34.6)$ & $2(15.4)$ & 0.2125 \\
\hline Hypopituitarism, hyperprolactinemia & $16(17.6)$ & $11(20.0)$ & $5(13.9)$ & 0.5775 & $13(16.7)$ & $3(23.1)$ & 0.6934 \\
\hline Diabetes insipidus & $15(16.5)$ & $9(16.4)$ & $6(16.7)$ & $>0.99$ & $12(15.4)$ & $3(23.1)$ & 0.4436 \\
\hline None & $5(5.5)$ & $3(5.5)$ & $2(5.6)$ & $>0.99$ & $4(5.3)$ & $1(7.7)$ & 0.5460 \\
\hline APG dysfunction & $64(70.3)$ & $36(65.5)$ & $28(77.8)$ & 0.2464 & $53(67.9)$ & $11(84.6)$ & 0.3304 \\
\hline \multicolumn{8}{|l|}{ T1-weighted MRI } \\
\hline High intensity & $37(40.7)$ & $20(36.4)$ & $17(47.2)$ & & $31(39.7)$ & $6(46.2)$ & \\
\hline Isointense & $29(31.9)$ & $21(38.2)$ & $8(22.2)$ & & $24(30.8)$ & $5(38.5)$ & \\
\hline Low intensity & $25(27.5)$ & $14(25.5)$ & $11(30.6)$ & 0.2758 & $23(29.5)$ & $2(15.4)$ & 0.5694 \\
\hline \multicolumn{8}{|l|}{ T2-weighted MRI } \\
\hline High intensity & $57(62.6)$ & $35(63.6)$ & $22(61.1)$ & & $49(62.8)$ & $8(61.5)$ & \\
\hline Isointense & $19(20.9)$ & $10(18.2)$ & $9(25.0)$ & & $15(19.2)$ & $4(30.8)$ & \\
\hline Low intensity & $15(16.5)$ & $10(18.2)$ & $5(13.9)$ & 0.6873 & $14(17.9)$ & $1(7.7)$ & 0.4905 \\
\hline Nodule & $17(18.7)$ & $8(14.5)$ & $9(40.0)$ & 0.2733 & $14(17.9)$ & $3(23.1)$ & 0.7035 \\
\hline Cyst size, median in $\mathrm{mm}$ & 18.0 & 15.0 & 18.0 & 0.0432 & 18.0 & 19.0 & 0.1677 \\
\hline \multicolumn{8}{|l|}{ Operative procedures } \\
\hline Use of fat graft & $55(60.4)$ & $33(60.0)$ & $22(61.1)$ & $>0.99$ & $47(60.3)$ & $8(61.5)$ & $>0.99$ \\
\hline \multicolumn{8}{|l|}{ Marsupialization } \\
\hline Suprasellar cistern & $37(40.7)$ & $21(38.2)$ & $16(44.4)$ & & $32(41.0)$ & $5(38.5)$ & \\
\hline Sphenoidal sinus & $6(6.6)$ & $4(7.3)$ & $2(5.6)$ & & $5(6.4)$ & $1(7.7)$ & \\
\hline None & $48(52.7)$ & $30(54.5)$ & $18(55.6)$ & 0.8218 & $41(52.6)$ & $7(53.8)$ & 0.9757 \\
\hline \multicolumn{8}{|l|}{ Pathological findings } \\
\hline Single & $60(65.9)$ & $40(72.7)$ & $20(55.6)$ & & $56(71.8)$ & $4(30.8)$ & \\
\hline Multiple & $10(11.0)$ & $4(7.3)$ & $6(16.7)$ & & $7(9.0)$ & $3(23.1)$ & \\
\hline Squamous metaplasia & $7(7.7)$ & $1(1.8)$ & $6(16.7)$ & 0.0130 & $2(2.6)$ & $5(38.5)$ & $<0.0001$ \\
\hline Unknown & 14 & 10 & 4 & & 13 & 1 & \\
\hline
\end{tabular}

APG = anterior pituitary gland.

* Values are number (\%) of patients unless otherwise indicated.

$\dagger$ Reoperation was performed in patients with symptomatic reaccumulation of RCC

size $(\mathrm{p}=0.0432)$. On pathological examination, their cyst walls were significantly more frequently found to contain multiple epithelial layers and squamous metaplasia ( $\mathrm{p}=$ $0.0130)$. On the other hand, there were no significant differences in the clinical symptoms, endocrinological examinations, or the operative procedures of the patients with a reaccumulation.

\section{The Clinical Features of Patients Who Underwent Reoperation}

The detailed clinical features at the initial surgery in patients who underwent reoperation are described in Table 1 . The patients who underwent reoperation were likely to have initially had a visual disturbance $(\mathrm{p}=0.0131)$, and their cyst walls were significantly more frequently found to contain multiple epithelial layers and squamous metaplasia on pathological examination $(\mathrm{p}<0.0001)$. There were no significant differences in the endocrinological examinations, MRI findings, or the operative procedures in the patients who underwent reoperation compared with those who did not undergo reoperation.

\section{Discussion}

The reaccumulation rates of postoperative RCCs have been shown to vary in surgically treated patients (Table 2). ${ }^{1,2,5,6,8,9,11,15,16,18}$ We observed a high incidence of reaccumulation after surgical treatment. The variations in the reaccumulation rates in previous reports are considered to be due to a number of reasons. Firstly, the surgical procedures of the past reports were not uniform. The total removal of the cyst wall is an entirely different procedure from the drainage and/or the biopsy of an RCC. The total removal of the cyst would theoretically ensure that no reac- 


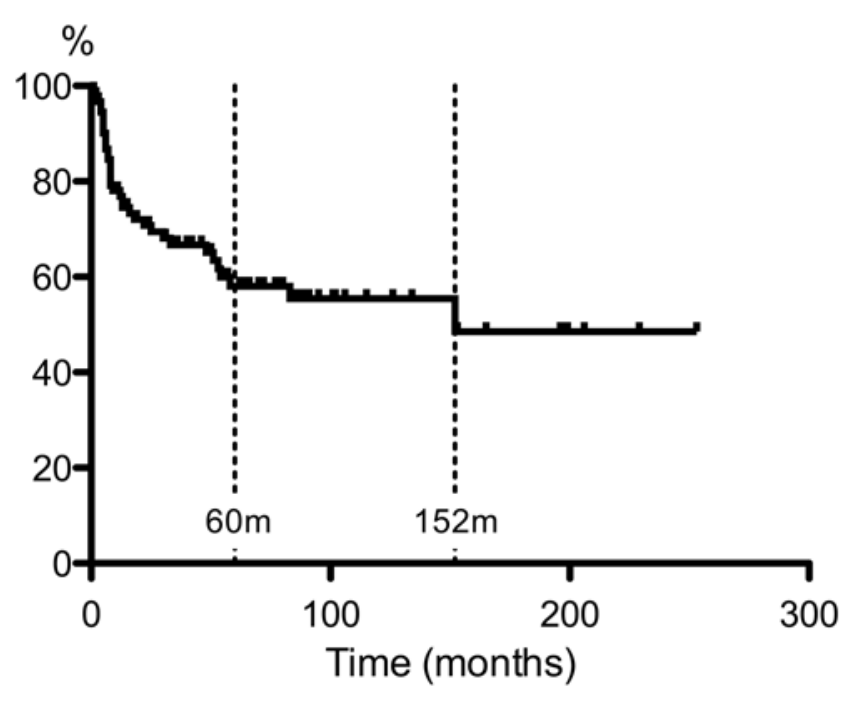

FIG. 4. Graph showing that reaccumulation occurred in the first 60 months after surgery in $34(94.4 \%)$ of the 36 patients in whom MRI demonstrated a reaccumulation of the cyst contents. The latest case of reaccumulation occurred 152 months after surgery.

cumulation of the cyst occurs, and it could thereby reduce the reaccumulation rate. Secondly, the follow-up protocols were not clarified in most reports. To detect the asymptomatic reaccumulation of an RCC, all patients must be monitored with routine postoperative MRI examinations. Regular MRI check-ups can increase the rate at which reaccumulation is observed. Thirdly, a long-term monitoring period is needed to assess the reaccumulation rate of RCCs. ${ }^{14,15}$ In the present study, the gradual increase in the reaccumulation rate of RCCs in the first 5 years after surgery implies that a follow-up period of at least 5 years is needed. With a short-term follow-up period investigators have the potential to underestimate the reaccumulation

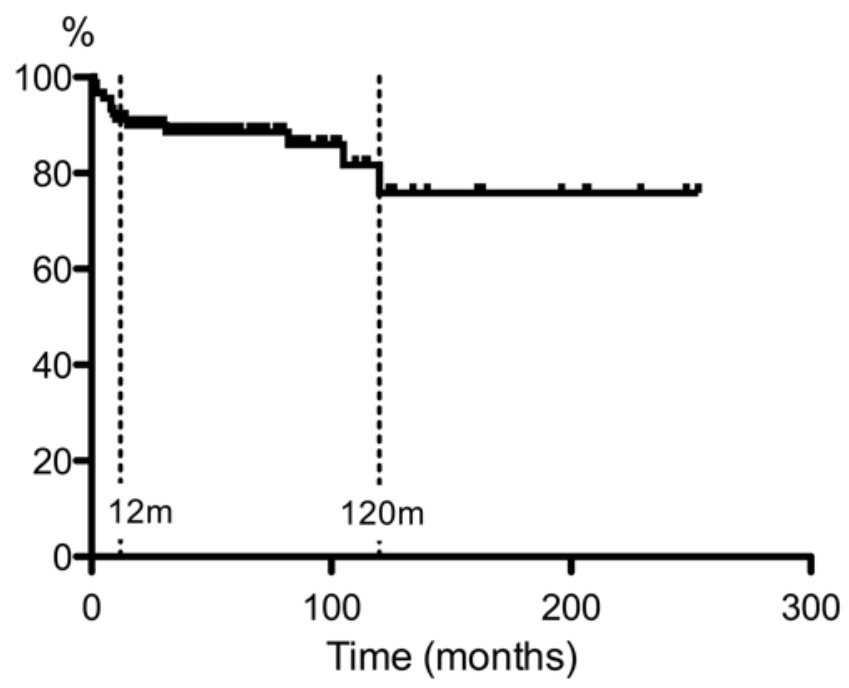

FIG. 5. Graph showing the bimodal timing of reoperation in the 13 patients with recurrent symptoms. Reoperations occurred either during the 1 st year after the initial surgery $(n=8,61.5 \%)$ or several years after the initial surgery $(n=3,23.1 \%)$. No patients required reoperations after 10 years of follow-up.
TABLE 2. The incidence of reaccumulation of cyst contents and reoperation in past reports

\begin{tabular}{lrcrc}
\hline \multicolumn{1}{c}{ Authors \& Year } & $\begin{array}{c}\text { No. of } \\
\text { Pts }\end{array}$ & $\begin{array}{r}\text { Reaccumulation } \\
(\%)\end{array}$ & $\begin{array}{r}\text { Reop } \\
(\%)\end{array}$ & $\begin{array}{c}\text { Mean FU } \\
(\mathrm{mos})\end{array}$ \\
\hline Kim et al., 2004 & 53 & NA & 11.3 & 31 \\
\hline Benveniste et al., 2004 & 62 & NA & 12.9 & 28 \\
\hline Aho et al., 2005 & 118 & 17.8 & 10.2 & $>60$ \\
\hline Potts et al., 2011 & 151 & 11.3 & 7.9 & 30 \\
\hline Wait et al., 2010 & 73 & 11.0 & 5.5 & 27 \\
\hline Higgins et al., 2011 & 61 & 18.0 & 13.1 & 60.5 \\
\hline Jahangiri et al., 2011 & 147 & 12.2 & NA & $23^{*}$ \\
\hline Lillehei et al., 2011 & 75 & 10.7 & NA & 3 \\
\hline Trifanescu et al., 2011 & 32 & 21.9 & 18.8 & 48 \\
\hline Zhong et al., 2012 & 41 & 14.6 & 4.9 & 16 \\
\hline Present study & 91 & 39.6 & 14.3 & 80.2 \\
\hline
\end{tabular}

$\mathrm{FU}=$ follow-up; $\mathrm{NA}=$ not available; Pts = patients.

* Value is the median.

rate of RCCs. We, therefore, assume that the actual reaccumulation rate of RCCs reported in a long-term period would be higher than that reported in a short-term period.

The factors associated with a higher rate of reaccumulation have been discussed and include a purely suprasellar location, large initial cyst size, enhancement of the lesion on MRI, the use of a fat graft in the cyst cavity, intraoperative CSF leakage, a residual cyst observed on postoperative MRI, and inflammation and reactive squamous metaplasia in the cyst wall., ${ }^{1,2,4,8,9,11,14,16,18}$ We showed that the predicting factors for the reaccumulation and reoperation of RCCs were clinical visual field defects, large initial cyst size, and squamous metaplasia. Above all, squamous metaplasia in the cyst wall might be the most important factor associated with the reaccumulation and reoperation of RCCs. Operative procedures were not found to affect the incidence of reaccumulation or the reoperation rate.

We suggest that there are 3 methods for preventing the reaccumulation of RCCs: completely removing the cyst wall, stopping the secretion of mucus from the epithelial cells, and making a permanent marsupialization of the RCC. When surgical procedures lacking these 3 methods are conducted, the reaccumulation of RCCs can be expected to occur due to the mucus-secreting cells that remain. The extended resection of the cyst wall is not conducted in the inital surgery for RCCs due to the high incidence of postoperative endocrine dysfunction, ${ }^{1,2,5,16}$ and the methods for preventing the secretion of mucus from the epithelial cells have not been established (the effectiveness of absolute ethanol has not been certified). ${ }^{9} \mathrm{We}$ attempted to create a permanent stoma between the RCC and the suprasellar cistern; however, the procedures could not reduce the reaccumulation rate of RCCs in the longterm period. Our results showed that it was technically difficult to make a permanent stoma for RCCs and suggest that while the operative procedures might have an effect on the short-term reaccumulation rate of RCCs, the difference might disappear over the long-term period. 


\section{Conclusions}

The presence of squamous metaplasia in the cyst wall is the most important factor associated with the reaccumulation and reoperation rates of RCCs that cannot be reduced using surgical devices. As the long-term rate of reaccumulation of RCC is high, a monitoring period of at least 5 years should be implemented to assess the degree of reaccumulation of RCCs after the initial surgery.

\section{Acknowledgments}

This study was supported in part by a Grant-in-Aid for Scientific Research from the Japan Society for the Promotion of Science (No. 15K103345D).

\section{References}

1. Aho CJ, Liu C, Zelman V, Couldwell WT, Weiss MH: Surgical outcomes in 118 patients with Rathke cleft cysts. J Neurosurg 102:189-193, 2005

2. Benveniste RJ, King WA, Walsh J, Lee JS, Naidich TP, Post KD: Surgery for Rathke cleft cysts: technical considerations and outcomes. J Neurosurg 101:577-584, 2004

3. Hama S, Arita K, Nishisaka T, Fukuhara T, Tominaga A, Sugiyama K, et al: Changes in the epithelium of Rathke cleft cyst associated with inflammation. J Neurosurg 96:209-216, 2002

4. Han SJ, Rolston JD, Jahangiri A, Aghi MK: Rathke's cleft cysts: review of natural history and surgical outcomes. J Neurooncol 117:197-203, 2014

5. Higgins DM, Van Gompel JJ, Nippoldt TB, Meyer FB: Symptomatic Rathke cleft cysts: extent of resection and surgical complications. Neurosurg Focus 31(1):E2, 2011

6. Jahangiri A, Molinaro AM, Tarapore PE, Blevins L Jr, Auguste KI, Gupta N, et al: Rathke cleft cysts in pediatric patients: presentation, surgical management, and postoperative outcomes. Neurosurg Focus 31(1):E3, 2011

7. Kim E: Symptomatic Rathke cleft cyst: clinical features and surgical outcomes. World Neurosurg 78:527-534, 2012

8. Kim JE, Kim JH, Kim OL, Paek SH, Kim DG, Chi JG, et al: Surgical treatment of symptomatic Rathke cleft cysts: clinical features and results with special attention to recurrence. $\mathbf{J}$ Neurosurg 100:33-40, 2004

9. Lillehei KO, Widdel L, Astete CAA, Wierman ME, Kleinschmidt-DeMasters BK, Kerr JM: Transsphenoidal resection of 82 Rathke cleft cysts: limited value of alcohol cauterization in reducing recurrence rates. J Neurosurg 114:310-317, 2011

10. Mendelson ZS, Husain Q, Elmoursi S, Svider PF, Eloy JA, Liu JK: Rathke's cleft cyst recurrence after transsphenoi- dal surgery: a meta-analysis of 1151 cases. J Clin Neurosci 21:378-385, 2014

11. Potts MB, Jahangiri A, Lamborn KR, Blevins LS, Kunwar S, Aghi MK: Suprasellar Rathke cleft cysts: clinical presentation and treatment outcomes. Neurosurgery 69:1058-1068, 2011

12. Sanno N, Oyama K, Tahara S, Teramoto A, Kato Y: A survey of pituitary incidentaloma in Japan. Eur J Endocrinol 149:123-127, 2003

13. Teramoto A, Hirakawa K, Sanno N, Osamura Y: Incidental pituitary lesions in 1,000 unselected autopsy specimens. Radiology 193:161-164, 1994

14. Trifanescu R, Ansorge O, Wass JAH, Grossman AB, Karavitaki N: Rathke's cleft cysts. Clin Endocrinol (Oxf) 76:151160, 2012

15. Trifanescu R, Stavrinides V, Plaha P, Cudlip S, Byrne JV, Ansorge O, et al: Outcome in surgically treated Rathke's cleft cysts: long-term monitoring needed. Eur J Endocrinol 165:33-37, 2011

16. Wait SD, Garrett MP, Little AS, Killory BD, White WL: Endocrinopathy, vision, headache, and recurrence after transsphenoidal surgery for Rathke cleft cysts. Neurosurgery 67:837-843, 2010

17. Zada G: Rathke cleft cysts: a review of clinical and surgical management. Neurosurg Focus 31(1):E1, 2011

18. Zhong W, You C, Jiang S, Huang S, Chen H, Liu J, et al: Symptomatic Rathke cleft cyst. J Clin Neurosci 19:501-508, 2012

\section{Disclosures}

The authors report no conflict of interest concerning the materials or methods used in this study or the findings specified in this paper.

\section{Author Contributions}

Conception and design: Kinoshita, Tominaga. Acquisition of data: Kinoshita, Tominaga, Usui, Arita, Sakoguchi. Analysis and interpretation of data: Kinoshita, Tominaga. Drafting the article: Kinoshita. Critically revising the article: Tominaga, Sugiyama, Kurisu. Reviewed submitted version of manuscript: all authors. Approved the final version of the manuscript on behalf of all authors: Kinoshita. Statistical analysis: Kinoshita. Administrative/ technical/material support: Tominaga, Sugiyama, Kurisu. Study supervision: Tominaga, Kurisu.

\section{Correspondence}

Yasuyuki Kinoshita, Department of Neurosurgery, Graduate School of Biomedical and Health Sciences, Hiroshima University, 1-2-3 Kasumi, Minami-ku, Hiroshima 734-8551, Japan. email address: y-kinoshita@hiroshima-u.ac.jp. 